\title{
Melis Erdur's Moral Argument Against Moral Realism
}

\section{Joshua Blanchard ${ }^{1}$}

Accepted: 25 March 2019 / Published online: 9 April 2019

(C) Springer Nature B.V. 2019

In a previous volume of this journal, Melis Erdur defends the provocative claim that postulating a stance-independent ground for morality constitutes a substantive moral mistake that is isomorphic to the substantive moral mistake that many realists attribute to antirealists. ${ }^{1}$ In this discussion I reconstruct Erdur's argument and raise two objections to the general framework in which it arises. I close by explaining why rejecting Erdur's approach doesn't preclude normatively criticizing metaethical theories.

\section{Erdur's Moral Argument against Moral Realism}

Erdur offers a preliminary argument for the claim that moral realism is a substantive moral theory. ${ }^{2}$ In brief, her argument is that metaethical views terminate chains of substantive moral why-questions, and as such must be substantively moral themselves. To illustrate, consider the following exchange between Eleazar and a Kantian, which I have loosely adapted from pp. 593-594 of Erdur's paper:

Esther: A's killing of B was not wrong.

Eleazar: Why?

Esther: Because it was self-defense.

Eleazar: Why does the fact that A's killing was self-defense count against its wrongness?

Esther: The fact that A's killing of B was self-defense makes a moral difference because it makes a difference to the universalizability of A's maxim - killing to save one's own life passes the universalization test, whereas killing for another reason might have failed it.

\footnotetext{
${ }^{1}$ Erdur (2016).

${ }^{2}$ Other philosophers who have defended some version of this claim include Ronald Dworkin (1996) and Matthew Kramer (2009).
}

Joshua Blanchard

jblanchard@oakland.edu

1 Oakland University, Mathematics and Science Center, Room 752, 146 Library Drive, Rochester, MI 48309-4479, USA 
Suppose that Eleazar is still unsatisfied. How might the exchange naturally proceed? Erdur imagines something like the following, in the event that Esther is not only a Kantian but a moral realist:

Eleazar: Why does the universalizability of a maxim render an action permissible?

Esther: Because an independent moral reality dictates that it does.

Once a "why" question is asked about an abstract normative theory, the appropriate next step, according to Erdur, is to ascend to the level of metaethics. Metaethical theories, therefore, "may naturally be heard as very general substantive moral claims about why (in the end) right things are right and wrong things are wrong" (595).

It is because moral realism amounts to a substantive moral claim (or set of claims) that it is subject to moral critique. Erdur's moral critique of realism is that it "makes the wrongness of anything always conditional on the existence of a dictate of some independent reality" (597), and that this conditional is morally problematic. For example, according to Erdur, the realist must say that genocide is ultimately wrong, not because of the pain and suffering it causes (these are reasons, but not ultimate reasons), but because an independent reality dictates that it is so. Here is Erdur's central argument:

[S] urely, the existence of an independently issued verdict - if there were such a verdict - that genocide is wrong would not be the main or ultimate reason why it is wrong. Genocide is wrong mainly and ultimately because of the pain and suffering and loss that it involves - regardless of whether or not the badness of such suffering and loss is confirmed by an independent reality. The mistake in realism, therefore, is that it holds independence from our judgments in such high regard that everything else, including what really makes things right or wrong, diminishes in importance.

This objection to realism is meant to be isomorphic to a common realist objection to antirealism: that the anti-realist makes moral truth objectionably dependent upon our attitudes. ${ }^{3}$

In place of giving either a realist or anti-realist answer to the final why-question above, Erdur commends giving no answer. She issues a principled defense of this quietist approach:

Whenever we make a moral judgment, say, that a case of killing is morally permissible, or that the fact that it is self-defense is the main reason why it is permissible, the question "Why?" is a legitimate question - because in moral deliberation our main task is to make a case for or against something. Equally important, however, is to make a good case. So, when we arrive at a point where anything further we say seems less plausible than what we have said so far, the best thing to do, from a moral perspective, is to dispense with the implausible additions and stop at the point where our case is strongest (601).

The point at which our answers seem less plausible than what we have said so far is the point at which we ascend to metaethics - in particular, moral metaphysics. Of course, Erdur is underselling her own point here. The realist answer to the final normative "why" question isn't just less plausible than previous answers, it can seem downright morally objectionable.

\footnotetext{
${ }^{3}$ Erdur cites Dworkin (1996, 2011) and Shafer-Landau (2003) as philosophers who have argued that, "If what is right or wrong is ultimately a function of what we think is right or wrong, as anti-realism claims it is, then even the most reprehensible things such as genocide, slavery, and torturing babies for fun, would be permissible if most people approved of them!" (592).
} 


\section{Eliding the Distinction between Normative and Meta-Ethics}

There is something odd about answering a substantively moral why-question with a metaethical statement - and, especially, a metaphysical metaethical statement. First, it is natural to think that traditional philosophical taxonomy itself is enough to prohibit metaethical answers to normative moral questions. After all, normative justification is one thing, metaphysical grounding another. But to motivate the broader point more concretely, it is useful to leave moral philosophy for the moment. Consider the following exchange about the physical law of inertia between Newton and Moses:

Newton: X's state of being at rest hasn't changed.

Moses: Why?

Newton: Because it has not been impressed upon by any force.

Moses: Why does the fact that an object has not been impressed upon by any force make a difference to its state of being at rest?

Newton: The fact that an object has not been impressed upon by any force makes a different to its state of rest because of the law of inertia - every body persists in its state of being at rest or of moving uniformly straight forward, except insofar as it is compelled to change its state by force impressed.

Suppose that Moses is still unsatisfied. How might the exchange naturally proceed? Here is what the analogue to an ascent to metaethics would look like, in the event that Newton is a scientific realist:

Moses: Why does the law of inertia make any difference to whether an object is at rest?

Newton: Because an independent reality dictates that it does.

It is immediately recognizable that Newton's final answer is not informative as a piece of physics. Insofar as Newton is doing physics, his final answer does not even so much as add anything to what he has said previously. As physics, the statement that an independent reality dictates that the law of inertia makes a difference to whether an object is at rest is just a restatement that the law of inertia makes a different to whether an object is at rest.

That said, Newton's final answer does not seem wholly off the mark or uninformativewhy might that be? I submit that the appearance of informativeness is explained by the fact that Newton's final answer is, or would be, informative as a piece of philosophy of science or the metaphysics of physics. As such, his answer constitutes a statement of scientific realism. (I am here conceiving of philosophy of science in relation to scientific discourse and practice as analogous to metaethics in relation to moral discourse and practice.) If this is right, then the dialogue plausibly contains an equivocation on Moses' "why" or Newton's "because". Only if Moses is equivocating from the "why" of physics to the "why" of the metaphysics of physics, or if Newton is likewise equivocating on "because," is Newton's final answer informative rather than a restatement. Here is a question better suited to Newton's final answer:

Moses: When you say that the law of inertia makes a difference to whether an object is at rest, are you saying that there really is such a law, written into the fabric of the Universe, or is that just a construct that helps us carry on scientifically?

Newton's final answer is relevant to this question, because this question is a question squarely in the domain of philosophy of science. And its relevance to this question explains why the answer seemed not wholly off the mark in the first place. 
An analogous analysis applies neatly to the exchange between Esther and Eleazar. Esther's final appeal to "an independent moral reality" adds nothing to the discussion if it is an answer to a question within normative ethics. As normative ethics, it is a mere restatement. But "Why does the universalizability of a maxim render an action permissible?" is a question in normative ethics, and so Esther's final answer is either uninformative or irrelevant. We can change Eleazar's question just as we changed Moses'. Here is a question better suited to Esther's final answer:

Eleazar: When you say that the universalizability of a maxim renders an action permissible, are you saying that there really is such a moral law, written into the fabric of the Universe, or is that just a construct that helps us carry on morally?

Esther's final answer is relevant to this question, because this question is a question squarely in the domain of metaethics. And its relevance to this question explains why the answer seemed not wholly off the mark in the first place. ${ }^{4}$

Once we disambiguate normative from metaethical "why" questions (and their "because" answers), we should not accept Erdur's view that metaethics provides the termination point for chains of normative why-questions. The illusion of informativeness is due to an equivocation. And if we do not accept Erdur's claim that metaethics provides the termination point for chains of normative why questions, then we need not worry about normative commitments being conditional on metaethical positions.

Recall that, according to Erdur, moral realists are committed to denying that "Genocide is wrong mainly and ultimately because of the pain and suffering and loss that it involvesregardless of whether or not the badness of such suffering and loss is confirmed by an independent reality." I have shown that there is an equivocation between the normative and metaethical "why" and "because." As grounds for the wrongness of genocide, pain and suffering are not competitors with the dictate of an independent reality. Rather, the realist view is that the ultimate normative grounds for the wrongness of genocide are to be understood metaphysically as constituted by an independent reality. It is not that the independent reality issues a further dictate beyond, "Genocide is wrong because of the pain and suffering and loss that it involves." Rather, that dictate just is an independent reality.

\section{The "Moral Work" of Robust Realism}

While Erdur's moral argument is aimed at all forms of moral realism that posit an independent reality, it is especially or most naturally aimed at versions of non-naturalist, robust realism. To show this, Erdur cites Shafer-Landau (2003) and Enoch (2011) as examples of realists who not only defend the existence of an independent moral reality, but who claim that this reality does "moral work" (600). In Erdur's paraphrase, they claim that "being a realist supplies one with an extra argument or rationale for standing one's ground in a moral argument - which amounts to significant moral work." As such, one might worry that these realists cannot avail themselves of my reply to Erdur, since their positions already blur the lines between normative and

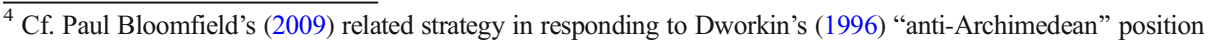
that all metaethical statements are translatable into normative statements. Bloomfield argues that Dworkin ignores the role of "context" in determining whether a putatively metaethical sentence is interpreted as normative (see especially pp. 290-293 in Bloomfield). Put in terms of Bloomfield's framework, I can be read as arguing that the contexts Erdur is addressing are clearly metaethical.
} 
metaethical theory. So, perhaps my objection to Erdur saves some forms of moral realism, but not some of the most prominent, robust versions that Erdur has in mind.

To see how even robust realists may avail themselves of my general strategy, consider the "moral work" to which Erdur refers. My view is that the moral (or broadly normative) claims of Shafer-Landau and Enoch on behalf of their metaethical theories are not themselves components of the theory. Rather, these are themselves independent moral claims that both philosophers make about why it is important that their theories are true-claims that would themselves receive realistic readings by these philosophers. Shafer-Landau and Enoch may very well be wrong about these moral claims, and yet their theories still be largely correct. ${ }^{5}$ This is because, even without moral claims in its favor, realism might still have the better share of Enoch's "plausibility points," and it might still be defensible along the lines of ShaferLandau's "companions in innocence" strategy with reference to domains like mathematics. To illustrate, take the only example Erdur cites: the importance of standing one's ground in moral argument. The supposed moral work done by robust realism here is that it establishes that there is an independent moral reality and corresponding truths that moral debates are about, and this in turn provides an explanation for why it is appropriate to stand one's ground in moral argument. The underlying thought here is that it makes the most sense to stand one's ground in an argument if the argument is not just, ultimately, about a matter of opinion, or something otherwise stance-dependent.

The claim that the particular kind of independence or objectivity characteristic of robust realism makes the best moral sense of standing one's ground might lead one to the following commitment:

If realism is false, then I will no longer stand my ground in moral disagreements.

For the sake of argument, I will concede that this is a morally objectionable commitment. The right response for the robust realist is simply to give up the relevant moral claim about robust realism - that its interpretation of independence is necessary to morally justify standing one's ground - not to give up robust realism itself. After all, perhaps there are other, non-realistic ways of making sense of standing one's ground-for example, with reference to the deep plans, cares, and other conative states that are part and parcel of the expressivist's interpretation of morality. Just as one might think that realism is on par with its competitors with respect to some other metaethical desideratum, e.g., in understanding moral counterfactuals (like that torturing babies would be wrong even if we didn't believe that it was), one might think that it is on par with respect to moral practices like standing one's ground.

Compare: a theistic philosopher may claim on behalf of theism that the existence of God secures meaning in life or the objectivity of moral value. ${ }^{6}$ Nevertheless, the claim that God is required for meaning in life need not itself be a component of theism; it is a normative claim about theism. It may, furthermore, be objectionable that someone would commit themselves to abandoning meaning or morality conditional on coming to believe that God does not exist, but

\footnotetext{
5 That being said, Enoch offers the autobiographical remark that if it were not for the moral importance he attributes to robust realism, he would "no longer care whether Robust Realism is true" (Enoch 2011, pp. 9-11, emphasis mine). But this is different from building the moral claim into the metaethical theory itself.

${ }^{6}$ See Wielenberg (2005) for systematic discussion of possible views in this vein.
} 
such a commitment is not constitutive of being a theist. Likewise, it would be objectionable that someone would commit themselves to abandoning first-order moral commitments conditional on coming to believe that realism is false, but such a commitment is not constitutive of being a realist.

It must be mentioned that Erdur seems to acknowledge and respond to a version of this reply (viz., that the moral claims about the theories are separate from the theories themselves) when she writes the following:

My objection to such a possibility, however, would essentially be the same as before: Does it really make moral sense to take some peculiar metaphysical truth about the world (which is devoid of any moral content itself, as we have assumed,) as the ultimate reason why we are justified in taking our judgments about genocide or slavery seriously, and standing our ground in such matters? If slavery, genocide, oppression of women, child abuse, racism and hate crimes, involved all that they involve, but that (morally empty) metaphysical condition did not hold, would not we be still justified (permitted, and perhaps obligated) to stand our ground when it comes to these issues?

Let us agree that it does not make moral sense to think about peculiar metaphysical truths as providing first-order moral reasons. It seems to me that Erdur's reply concedes the main point at issue by allowing that the realist metaphysic might lack moral content. All Erdur has shown in the passage just quoted is that conditionalizing a moral commitment on a metaphysical reality may be morally objectionable without the conditionalization itself being part of what it is to believe the corresponding metaethical theory. But by allowing that robust realists may separate metaphysical and normative grounds for their first-order moral commitments, Erdur abandons what was the main claim of her paper: that there is something morally objectionable in moral realism per se. Put more vividly, Erdur is surely correct that it is morally wrong to be committed to the permissibility of genocide if the realist metaphysic is false. This merely shows that realists ought not be so committed, not that such a commitment is constitutive of their realism.

\section{Conditionalizing on Metaethical Vs. Normative Moral Reality}

Erdur claims that realists (and antirealists) have the second-order commitment to give up their first-order moral commitments in the event that their metaphysics tells them to do so. Once we have rightly separated the roles of normative and metaethics, it is clear that the hypothetical component of the commitment is not even possible. Using Erdur's terminology, the only "reality" that can tell us what to do is normative reality. Hence, as far as theories go, it is the best normative moral theory that should tell us what we morally ought to do. The best metaethical theory only tells us the metaphysical, epistemology, semantic, and perhaps psychological status or nature of the best normative moral theory.

If this is the right way to understand normative and metaethics, then the closest hypotheticals to Erdur's will not-indeed, cannot-have the morally objectionable results that she worries about. The only sense in which an "independent moral reality" can "dictate" something - say, that $\mathrm{p}$ is morally wrong - that opposes what we currently think is by constituting the metaphysical, epistemological, semantic, and psychological underpinnings of the true normative theory's dictation that $\mathrm{p}$ is morally wrong. But it is hardly morally objectionable to be committed to thinking that $\mathrm{p}$ is morally wrong in the event that $\mathrm{p}$ is morally wrong. 


\section{Are Metaethical Theories Immune from Normative Critique?}

Based on my replies to Erdur, one might suspect that I want to isolate metaethical theorizing from normative theorizing entirely. But this is not the case. In my view, metaethical theories are just as susceptible to normative (including moral) evaluation as any other philosophical theories. Consider, again, the example of theism in the philosophy of religion. Theism (not to be confused here with Divine Command Theory, of which it is just a component) is not a substantive moral theory, or a moral theory of any kind, but this does not make theism immune from normative or moral critique. Recently, in fact, philosophers have devoted considerable attention to questions about whether (and in what ways) it would be good or bad if theism were true. ${ }^{7}$ The fact that we can wonder whether or not God's existence would be good does not mean that theism is a normative theory.

Although these questions are seldom pursued, we can ask the same sorts of questions about metaethics, without needing to think that metaethics is really just normative ethics in disguise. We can ask questions like, "Would it be better if moral realism rather than antirealism were true?", or "Would it really be so bad if nihilism were true?", 8 or any number of other similar normative questions about metaethics.

My complaint about eliding the distinction between normative and metaethics is not a complaint about relating them in any way whatsoever. Questions about the normative or evaluative upshot of different metaethical theories are important and interesting questions that philosophers should devote more attention to, and Erdur is to be praised for doing so. But we should not lose site of the real distinction between them in the course of pursuing this worthy subject.

\section{References}

Bloomfield P (2009) Archimedeanism and why Metaethics matters. In: Russ Shafer-Landau (ed), Oxford Studies in Metaethics 4:283-302

Dworkin R (1996) Objectivity and truth: You'd better believe it. Philos Public Aff 25(2):87-139

Dworkin R (2011) Justice for hedgehogs. Harvard University Press, Cambridge

Enoch D (2011) Taking morality seriously: a defense of robust realism. Oxford: Oxford University Press

Erdur M (2016) A Moral Argument Against Moral Realism. Ethical Theory Moral Pract 19(3):591-602

Kahane G (2016) If nothing matters. Nous 50(2):1-27

Kraay K (ed) (2018) Does god matter? Essays on the axiological consequences of theism. Routledge, New York Kramer MH (2009) Moral realism as a moral doctrine. Oxford: Wiley-Blackwell

Shafer-Landau R (2003) Moral realism: a Defence. Oxford: Oxford University Press

Wielenberg E (2005) Value and virtue in a Godless University. Cambridge: Cambridge University Press

Publisher's Note Springer Nature remains neutral with regard to jurisdictional claims in published maps and institutional affiliations.

\footnotetext{
${ }^{7}$ See especially the volume edited by Klaas Kraay (2018), Does God Matter? Essays on the Axiological Consequences of Theism.

${ }^{8}$ Guy Kahane (2016) recently asks this question in his, "If Nothing Matters," though he ultimately argues that the question does not make sense. Whether the question makes sense partly depends on whether we have in mind global or a domain-specific form of nihilism, for example moral nihilism. If we have in mind only the latter, then it seems that it can make sense to judge that the truth of (moral) nihilism would be (non-morally) bad.
} 